\title{
Recent Progress in the Study of Surface Observation Using Scanning Probe Microscopy
}

\author{
Hiroyuki Masuda \\ National Research Institute for Metals, Tsukuba 305-0047, Japan
}

\begin{abstract}
The STM was invented by Binnig et $_{\text {al }}{ }^{(1)}$ in 1981 at IBM Research Center. In order to overcome the defect that the STM can be used only conductive materials, the atomic force microscope (AFM) was invented by Binnig in cooperation with the University of Stanford. Both microscopes consist of the XYZ stage of piezo actuator that deforms by applying the voltage and very sharp probe is scanned in the X-Y direction to obtain the data. The microscopes based on this principle are called scanning probe microscopes (SPM). The most notable feature of the SPM is that the SPM can be used not only in air but also in liquid. Many types of the SPM are commonly available now. In the present paper, the application of SPM on observation of water film and water cluster is mainly discussed by using recent SPM research works of the author.
\end{abstract}

(Received October 21, 1998; In Final Form December 17, 1998)

Keywords: scanning probe microscope, water film, water cluster, surface potential, relative humidity

\section{Introduction}

Many scientists had dreamed to move and look at the atom directly. The invention of a scanning tunneling microscope (STM) made the dream realize. The STM was invented by Binnig et al. ${ }^{(1)}$ in 1981 on the IBM Research Center. In order to overcome the defect that the STM can be used only conductive materials, the atomic force microscope (AFM) was invented by Binnig in cooperation with Stanford University. These microscopes consist of the XYZ stage of piezo actuator that deforms by applying the voltage and very sharp probe is scanned at $\mathrm{X}-\mathrm{Y}$ direction to obtain the data. The microscopes based on this principle are called scanning probe microscopes (SPM). Many types of the SPM, such as the lateral force modulation friction force microscope (LM-FFM), the visco-elasticity atomic force microscope (VE-AFM) and the Kelvin force microscope (KFM) are now commercially available. The most notable feature of the SPM is that the SPM can be used not only in air but also in liquid. Many overviews of SPM have been published in Japanese $^{(2)-(7)}$. In the present paper, recent researches on the observation of small water droplets and on surface potential measurement will be described.

\section{Principle of Observation of Liquid}

The observation of liquid by AFM was first tried by $\mathrm{Hu}$ et al. ${ }^{\left({ }^{()(9)}\right.}$ They used the scanning polarization force microscope. In this method, they used conductive tip and applied the voltage on the tip. In this case, the relation between the force and distance from tip under various die- lectric constants can be represented as in Fig. 1. Under a constant force condition, the change of tip height occurred when the dielectric constant was changed. Using the principle they succeeded to observe water film on mica at $35 \% \mathrm{RH}$. This method seems to be useful in observing the material with high conductivity adsorbed on insulators such as mica, but not useful to observe the material adsorbed on the materials with a similar dielectric constant. The effect of electrostatic force on the force curve on graphite was studied by Hao et al. ${ }^{(10)}$ They showed that the force curve of static tip at non-contact region is strongly affected by applying the voltage. The author ${ }^{(11)}$ also used conductive tip and applied the voltage under occilating tip mode. Figure 2 shows the effect of the applied voltage the force curve on graphite. The amplitude decreases rapidly when the tip begins to contact the graphite. The resolution of the obtained shape increases with increasing the decay of force curve, so the resolution of the obtained image is high under the cyclic contact condition and low under the non-contact condition when the applied voltage is zero. When the voltage is applied on the tip, the force curve changes especially in the non-contact region. The decay of force curve increases at the non-contact region. Therefore, the resolution of the obtained shape increases. Obtaining adsorbed water on materials, the most important thing to observe the soft materials is that the applied force should be minimized. That is, using a soft canti-lever, a small drive amplitude and a high setpoint are essential for operating the SPM. The real non-contact mode is most suitable for obtaining the image of soft materials, however it is possible to obtain the image of soft materials by a cyclic contact mode with minimized applied force. 


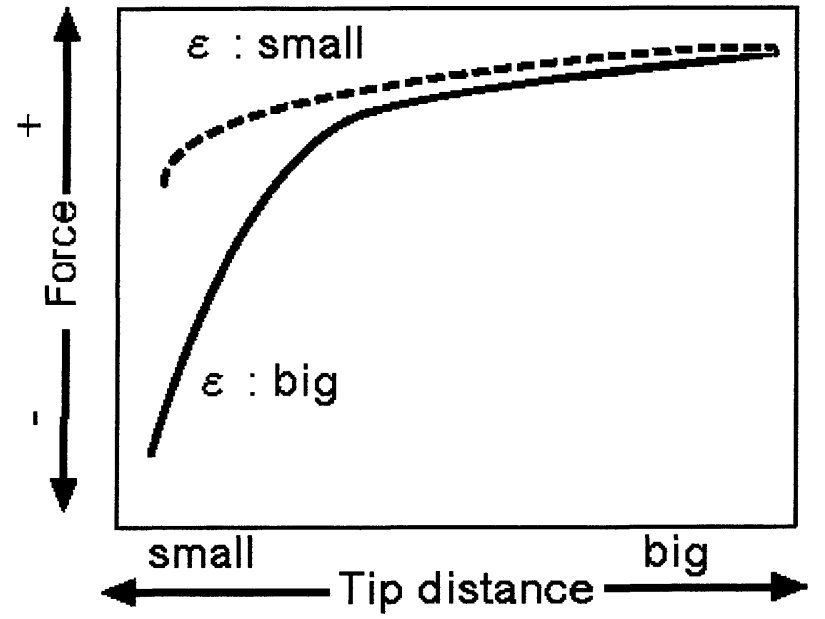

Fig. 1 Force vs. distance curve under applied voltage conditions.
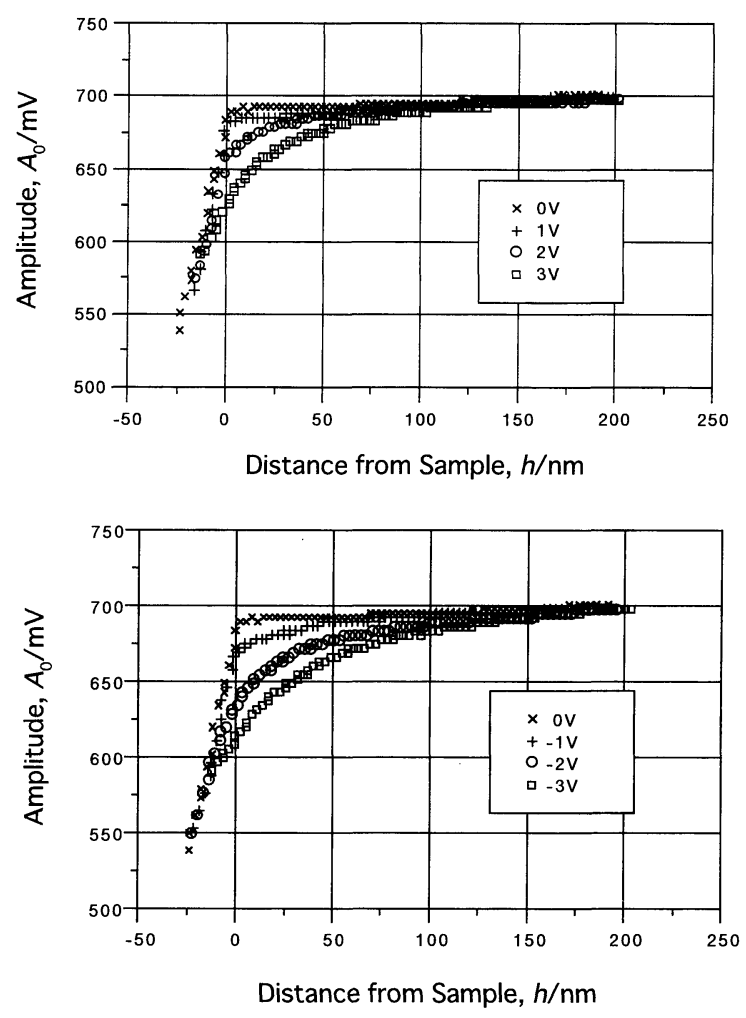

Fig. 2 Effect of bias on force curve on graphite.

\section{Observation of Water Film and Water Cluster ${ }^{(11)-(13)}$}

In order to get the images of water films or water clusters adsorbed in materials we must use a clean and atomically flat surface. Graphite and mica are suitable materials since we can easily be create a flat and clean surface in air by peeling off the surface of these materials. Figures 3 and 4 show the AFM images of the graphite and mica surfaces freshly created by peeling off the surface, respectively. Mono-layer and multi-layer steps were observed on the AFM image of the graphite surface freshly created by peeling off the surface, but no dust was observed. In the case of mica, neither step nor dust was ob-

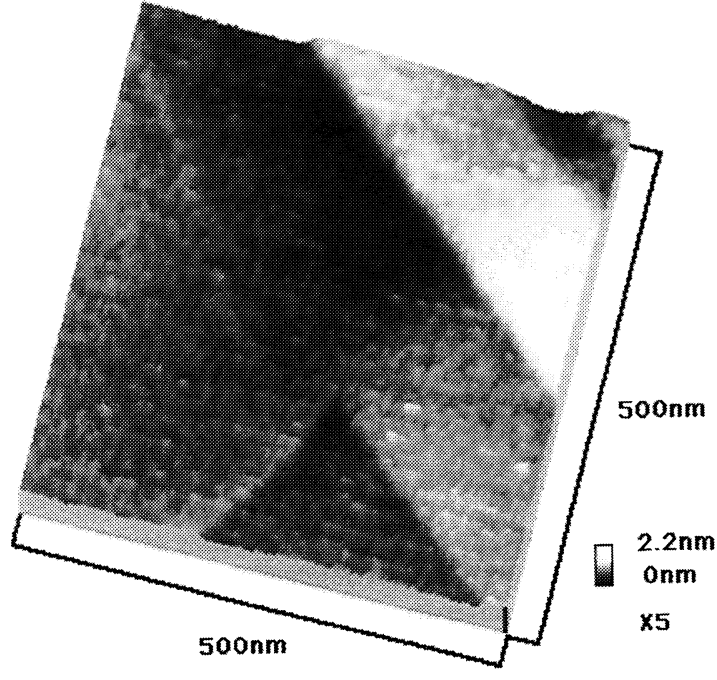

Fig. 3 AFM image of graphite surface freshly created by peeling off the surface (bias $=0 \mathrm{~V}$ ).

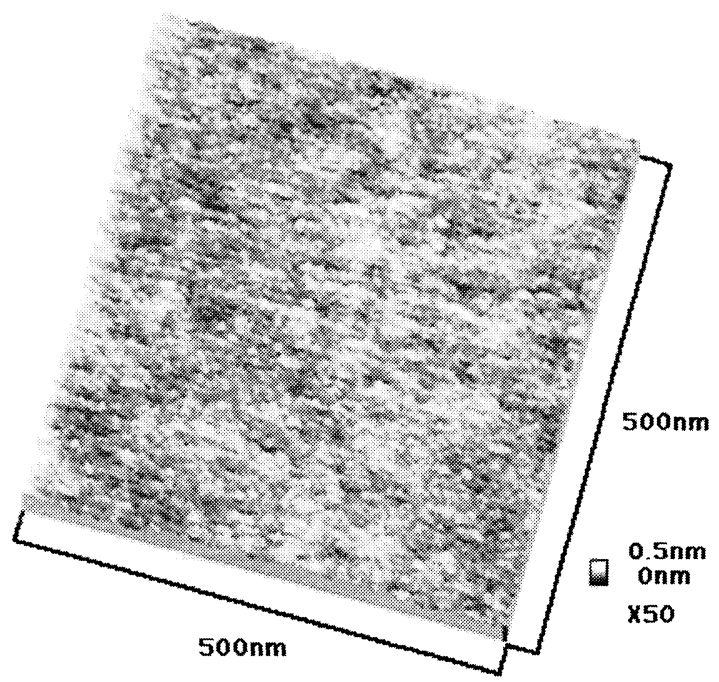

Fig. 4 AFM image of mica surface freshly created by peeling off the surface $($ bias $=0 \mathrm{~V})$.

served on the surface freshly created by peeling off the surface. Similar images were observed on the graphite and mica surface freshly created by peeling off the surface and sprayed by cleaner gas. This indicates that the spraying does not make any droplet on the graphite and mica surface. After pouring pure water (distilled and deionized water) and spraying cleaner gas on the graphite surface, the water droplets can be seen on the graphite surface (Fig. 5). A number of water droplets composed of smaller water droplets (may be water cluster) were observed and they tended to gather by step when the density of water droplets was low. The size of water droplets adhered at step were usually smaller than the other droplets. These water droplets were very stable and did not evaporate more than several days. Figure 6 show the AFM image of the mica surface after peeling off the surface, pouring pure water and spraying a cleaner gas. In 


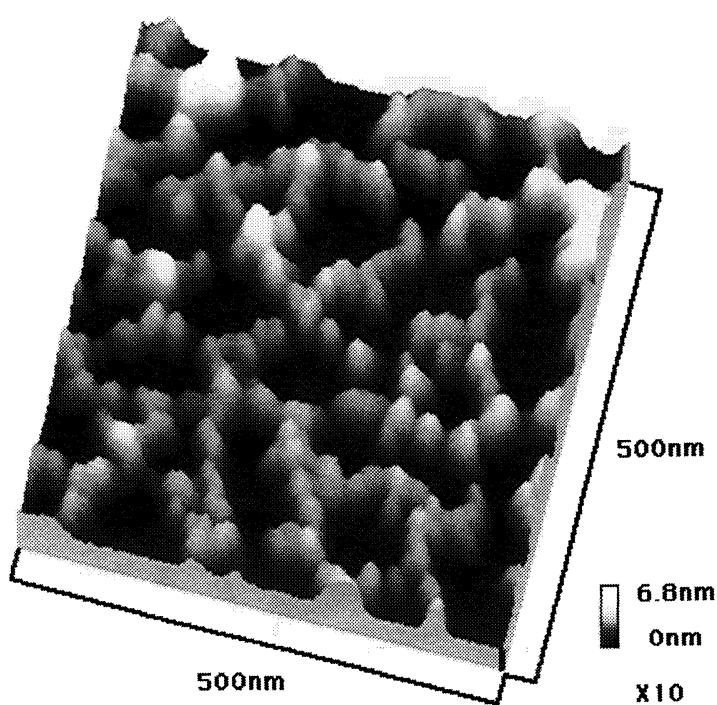

Fig. 5 AFM images of graphite surface pouring water and (a) spraying (bias $=2.5 \mathrm{~V}$ ) and $(\mathrm{b})$ dried naturally (bias $=2.5 \mathrm{~V}$ ).

most cases, surfaces were covered by the water films of about $1 \mathrm{~nm}$ thickness. The size of water droplets on the mica was almost the same as that on graphite. The difference of morphology from graphite was the existence of a thick water film. This water film can be observed when pure water is poured on the graphite surface for a rather long time (Fig. 7). These water films and water droplets can be easily moved by contact mode scanning. Figure 8 shows the movement of water droplets on graphite without water film by contact mode scanning. The force applied during contact mode scanning was $1.8 \mathrm{nN}$. The contact mode scanning was done only in the middle region of the image. The water droplets were moved by scanning and the small water droplets become a big droplet. However, no water film was observed on the contact mode scanned area. Figures 9 and 10 show the movement of water droplets and films on graphite and mica with water film by contact mode scanning. The water droplets were moved by scanning and the small water

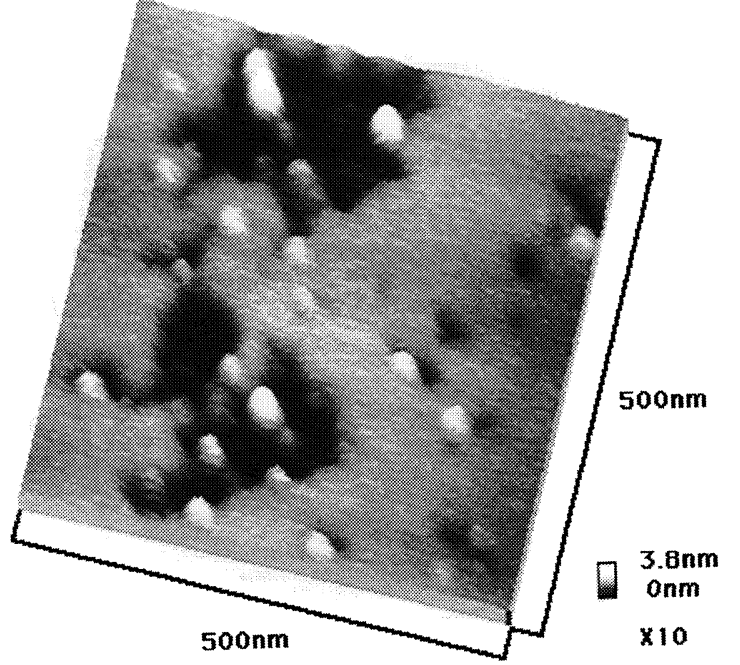

Fig. 6 AFM images of water droplets on mica surface pouring water and then spraying (bias $=2.5 \mathrm{~V}$ ). (a) Water droplets and (b) water film were observed on most area.

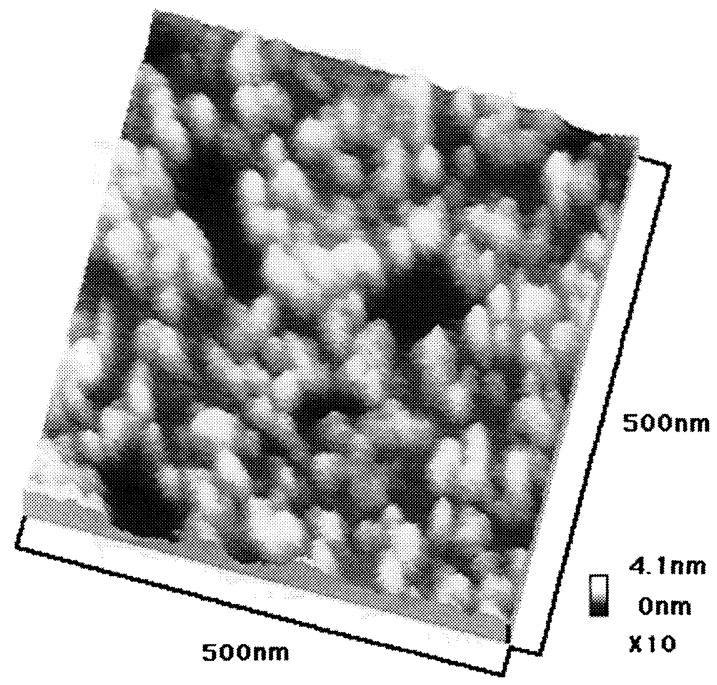

Fig. 7 AFM images of graphite surface pouring water and dried naturally (bias $=2.5 \mathrm{~V}$ ). (a)

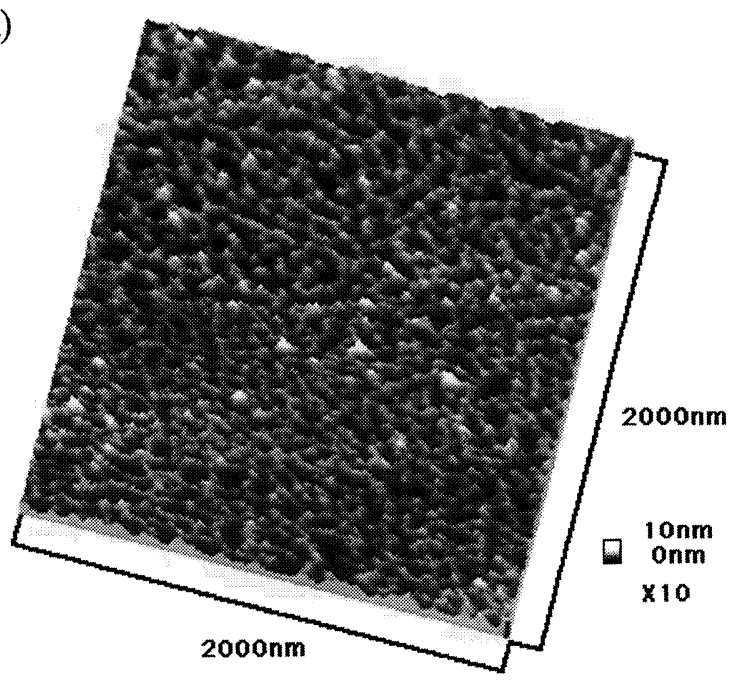

(b)

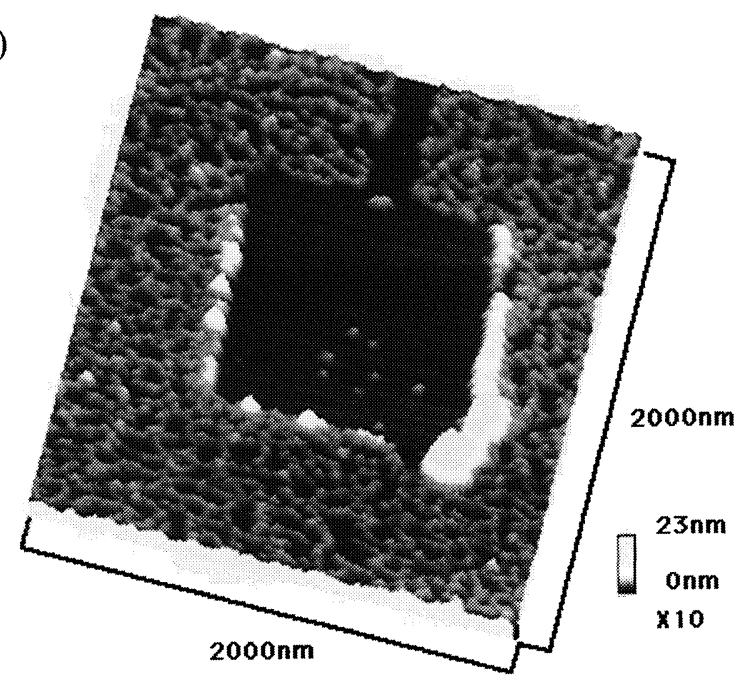

Fig. 8 AFM image of graphite surface with pure water droplets (a) before and (b) after contact mode scanning (bias=2.5 V). 

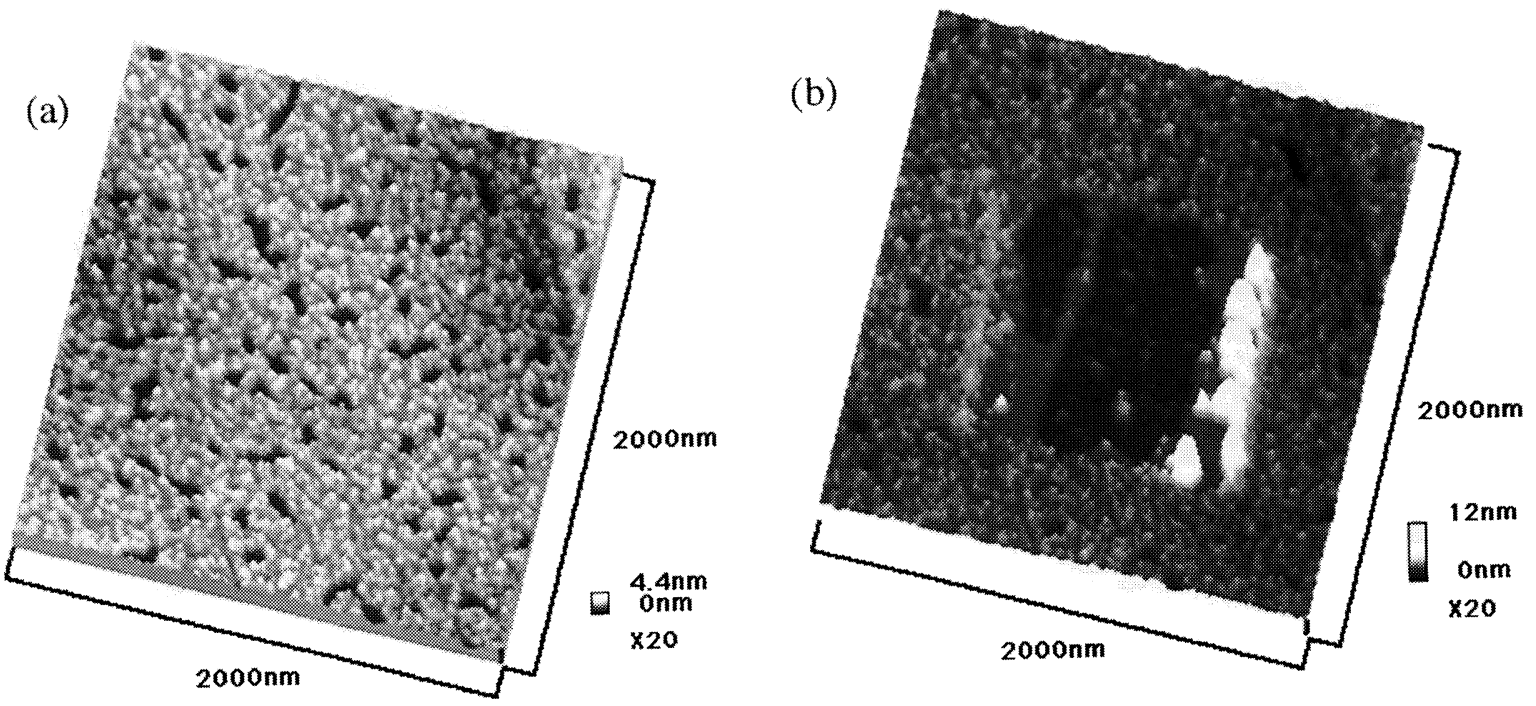

Fig. 9 AFM image of graphite surface with pure water droplets and film (a) before and (b) after contact mode scanning $($ bias $=2.5 \mathrm{~V}$ ).
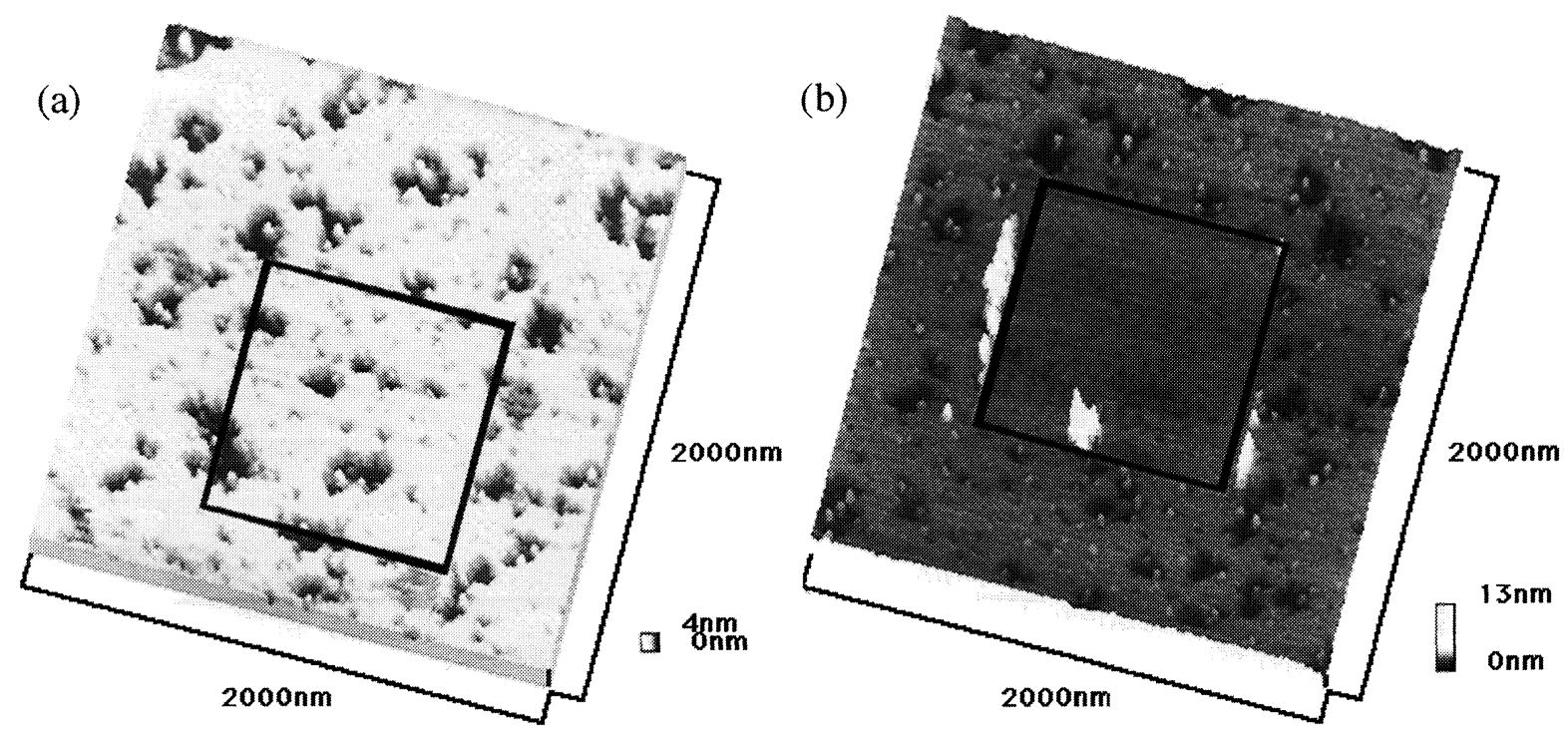

Fig. 10 AFM image of mica surface with pure water droplets and film (a) before and (b) after contact mode scanning (bias $=2.5 \mathrm{~V}$ ).
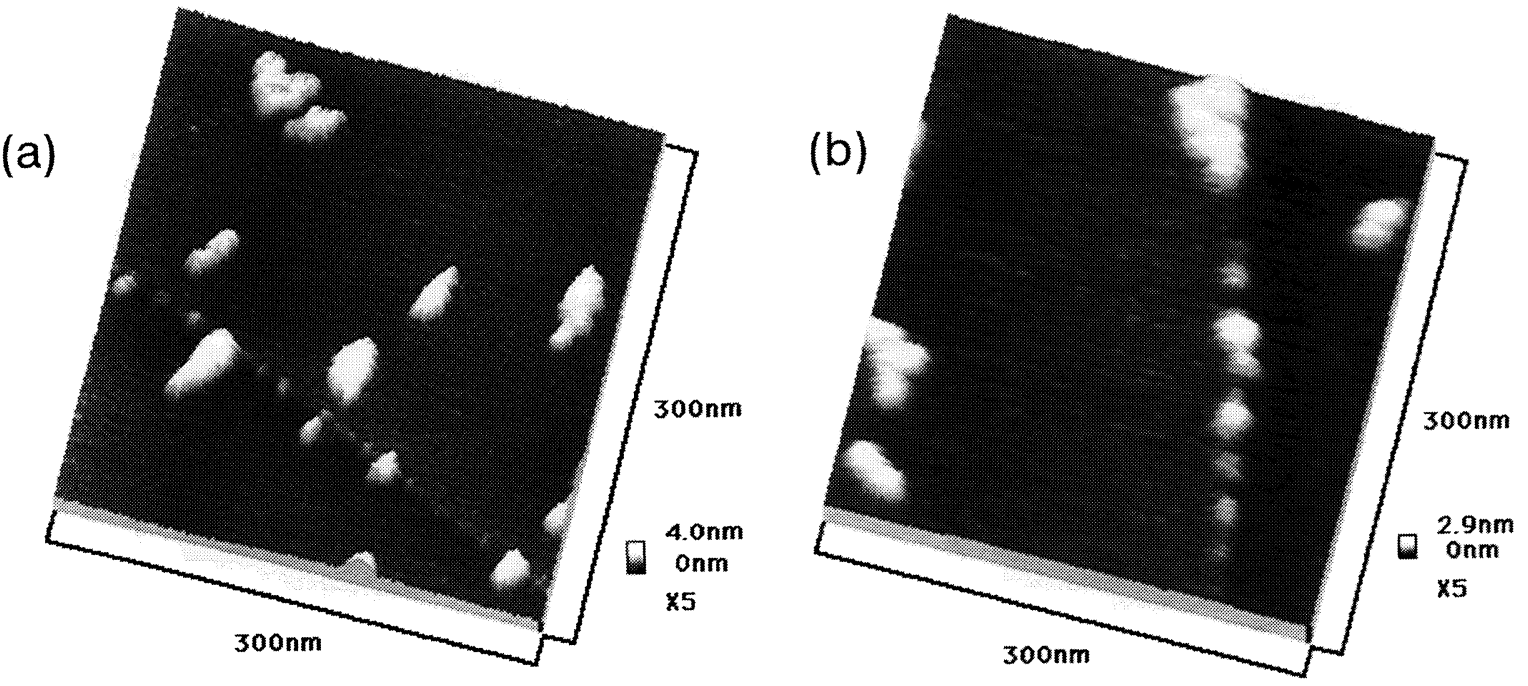

Fig. 11 Effect of tip radius on the AFM image of water droplets on graphite. (a) Image taken by tip radius of 2 to $5 \mathrm{~nm}$ and (b) image taken by tip radius of 20 to $30 \mathrm{~nm}$. 
droplets become a big droplet, while the water film could not removed perfectly by this scanning. The sizes of small water droplets were between 15 and $25 \mathrm{~nm}$ in width and between $1 \mathrm{~nm}$ and $2.5 \mathrm{~nm}$ in height. The tip used was the gold-coated Si tip and its radius of curvature $R$ was around 20 to $30 \mathrm{~nm}$. If we assume the shape of the water droplet is hemisphere, the expanding ratio of image by the tip is expressed as $(2 R / r+1)^{1 / 2}$, where $r$ is the radius of curvature of water droplet. If we use this equation by assuming the tip radius of curvature is $25 \mathrm{~nm}$, the expanding ratio of width becomes 5.1 when the height of water droplet is $2 \mathrm{~nm}$. This indicates the hemisphere shape of water droplet of $2 \mathrm{~nm}$ height is observed as the water droplets of $20 \mathrm{~nm}$ in width. In order to confirm the effect of tip radius on the expanding ratio on image, super tips 2 to $5 \mathrm{~nm}$ in tip radius are used to observe the water droplets. In this case, if the tip radius of curvature is assumed as $3 \mathrm{~nm}$, water droplets of $8 \mathrm{~nm}$ in width is expected to observe when the height of water droplet is $2 \mathrm{~nm}$. Figure 11 shows the effect of radius of tip curvature on AFM image of water droplets on graphite. It is obvious from the image that the sizes of small water droplets are less than $10 \mathrm{~nm}$ when the image was taken by super tip. The difference in the size of the on water droplets is due to the difference in the tip radius of the curvature. From these results, there is a possibility that the width of these water droplets is around $4 \mathrm{~nm}$.

\section{Nucleation and Growth of Water Droplets ${ }^{(14)}$}

The effect of relative humidity on the growth of average water thickness has been studied by $\mathrm{QCM}^{(15)}$ (quartz crystal microbalance method), FT-IR ${ }^{(16)}$ and elipsometry. However, no in-situ observation has been done by AFM. Using an environmental cell as shown in Fig. $\mathbf{1 2}$ and a relative humidity controller, the author succeeded in observing the growth and shrink of the water droplets on gold under relative humidity controlled conditions. The specimen used was a gold-coated quartz crystal of $10 \mathrm{MHz}$ resonant frequency. Figure 13 show AFM image of the gold-coated quartz crystals with different surface conditions. The amount of small particles adsorbed on the surface increased as the specimen was kept at $40 \%$ relative humidity. The adsorbed small particles were easily moved and small particles join to become a big droplet by contact mode scanning (Fig. 14). Figure 15 shows the effect of relative humidity on the behavior of water droplets on gold surface. When the relative humidity was increased from 25 to $80 \%$, the growth of water droplet was observed. The sizes of water droplets grown at $80 \%$ relative humidity were 40 to $70 \mathrm{~nm}$ in diameter and 5 to $15 \mathrm{~nm}$ in height. The big droplet formed by the contact mode scanning also grew at $80 \%$ relative humidity, so the small particles were found water droplets. Figure 16 shows the detail of square area in Fig. 15. Nucleation and growth of water droplet were observed at $80 \%$ relative humidity as indicated by arrows. The growth and shrink of the water droplet is reversible process. When the relative humidity was $25 \%$, only few

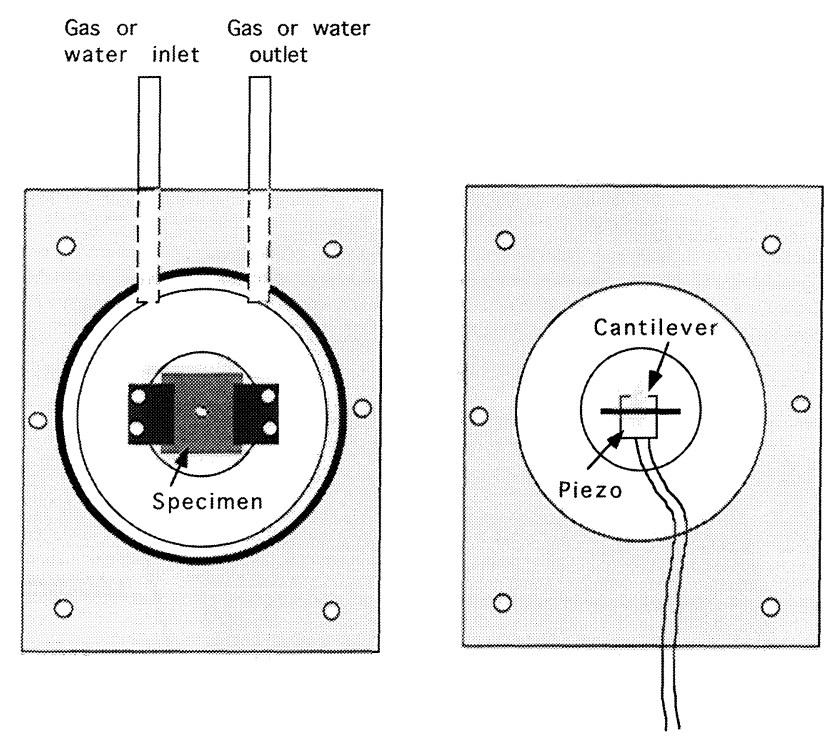

Fig. 12 Schematic representation of environmental cell for SPM.

water droplets of which diameter is bigger than $50 \mathrm{~nm}$ could be seen on the gold surface (Fig. 17(a)). The growth of water droplet began when the relative humidity exceeded $60 \%$ (Fig. 17(b)). The growth of water droplet continued with increasing the relative humidity (Fig. 17(c)). The shrink of water droplet occurred with decreasing the relative humidity and most of water droplets disappeared at $25 \%$ relative humidity (Fig. 17(d)). These results agree well with the experimental results obtained by QCM measurement. The growth and shrink mechanism of water droplet can be explained as the change of the equilibrium ion concentration with the relative humidity if some ions exist in the water droplet.

\section{Principle of Surface Potential Measurement}

Surface potential measurement by AFM, which is called the Kelvin Force microscope (KFM) or the Electric force microscope (EFM), was first done by Martin et $a l .{ }^{(17)}$, and many applications ${ }^{(18)-(20)}$ have been done by using this method. The principle of surface measurement is as follows: The electrostatic force on a conducting tip held close to a conducting surface is given by

$$
F=-\frac{V^{2}}{2} \frac{\partial C}{\partial z}
$$

where $V$ is the potential difference between tip and specimen, $C$ is the capacitance between tip and specimen, and $z$ is the distance between tip and specimen. Consider the force on the tip due to a potential difference $V$;

$$
V=V_{\mathrm{dc}}+V_{\mathrm{ac}} \sin (\omega t)
$$

where $\omega$ is frequency of applied ac voltage. The amplitude of vibration of the tip, $A$ will be given by

$$
A=2 \frac{\partial C}{\partial z} V_{\mathrm{dc}} V_{\mathrm{ac}}
$$

where $V_{\mathrm{dc}}=V_{\text {tip }}-V_{\text {sample }}$. If we servo control dc level until 


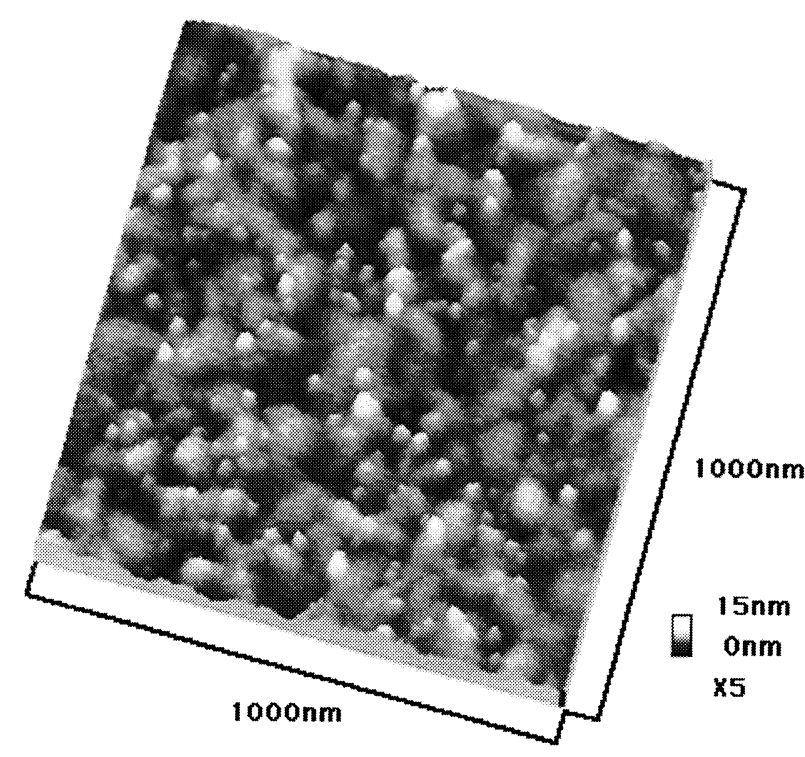

(a) new one

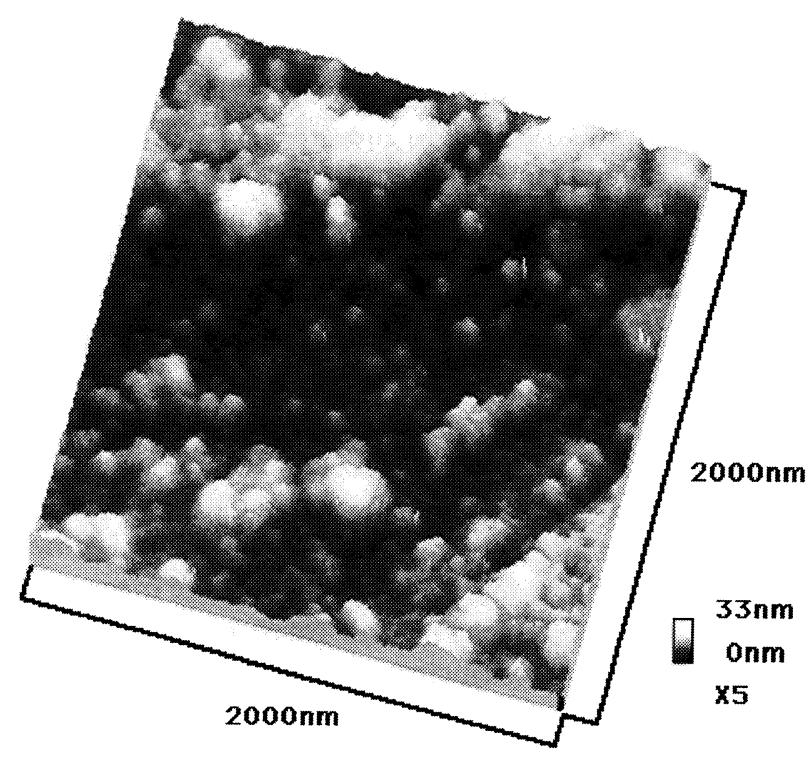

(c) specimen ultra-sonically cleaned with aceton.

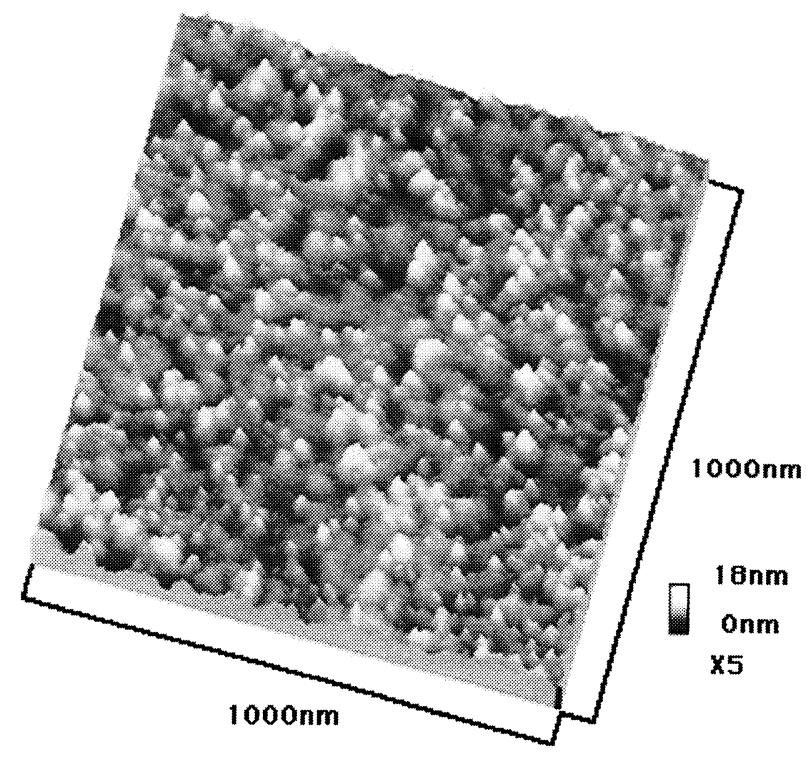

(b) specimen kept at relative humidity of $40 \%$ for 2 weeks.

Fig. 13 Surface condition of quartz crystals. 


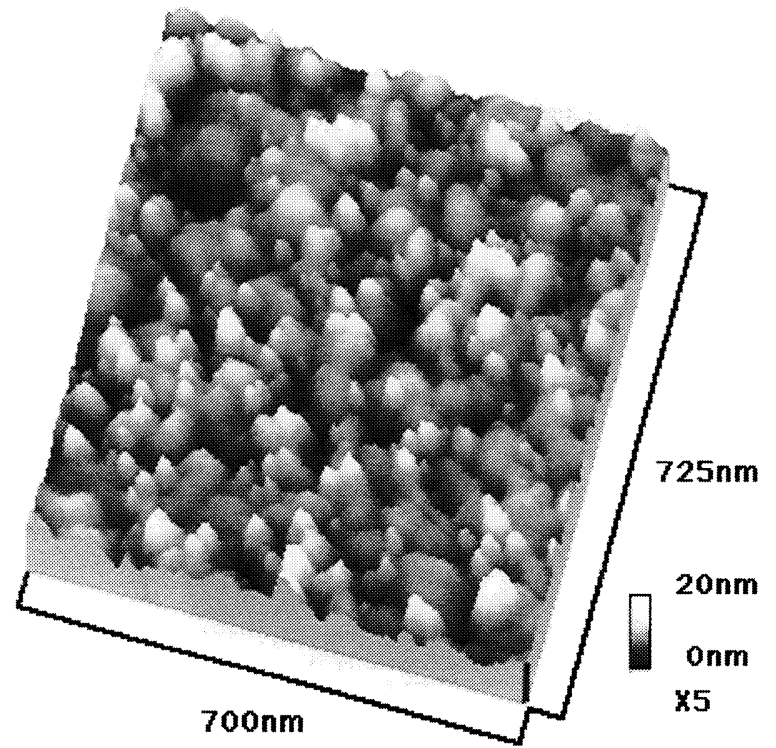

(a) non-contact mode scanning image before contact mode scanning.

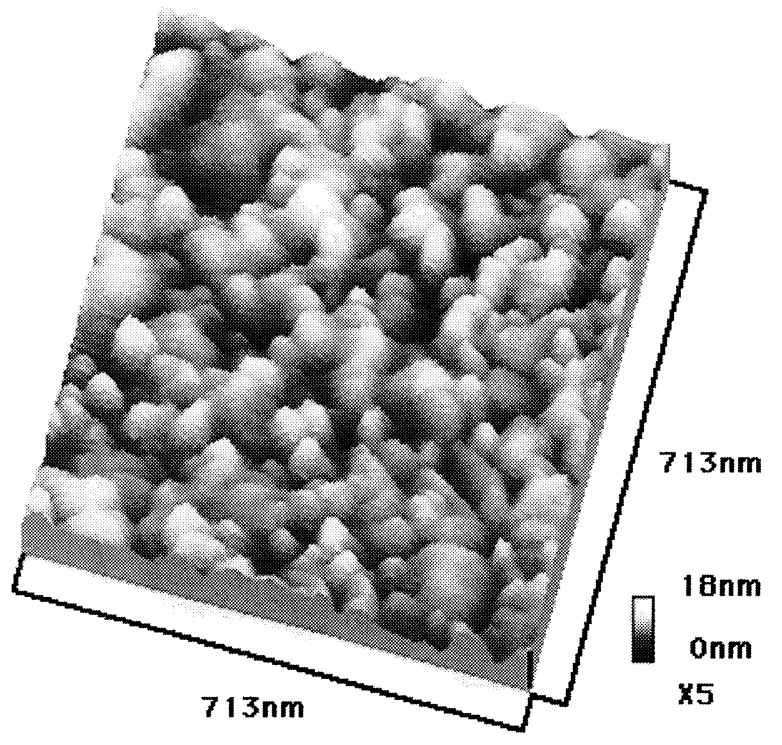

(c) contact mode scanning image.

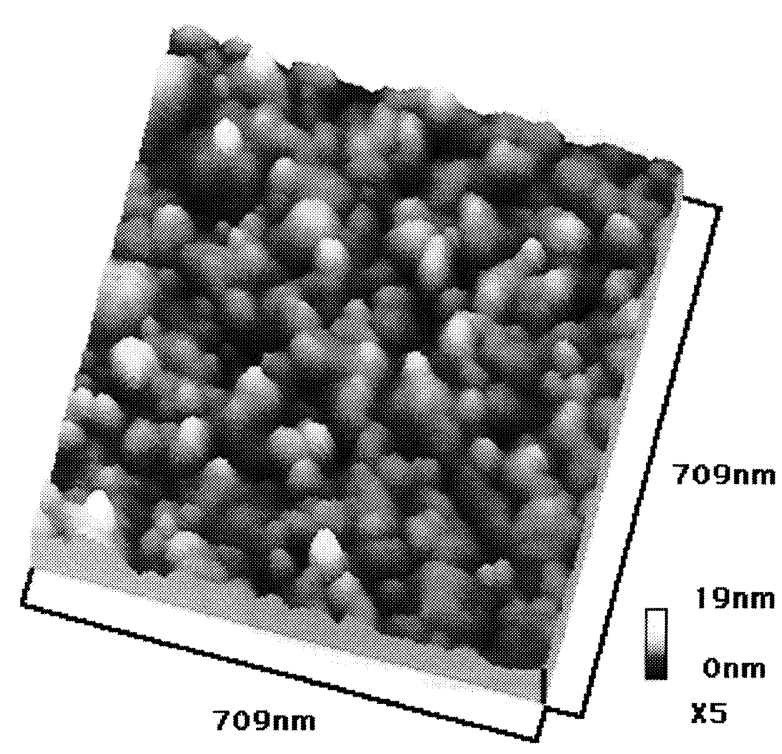

(b) non-contact mode scanning image after contact mode scanning.

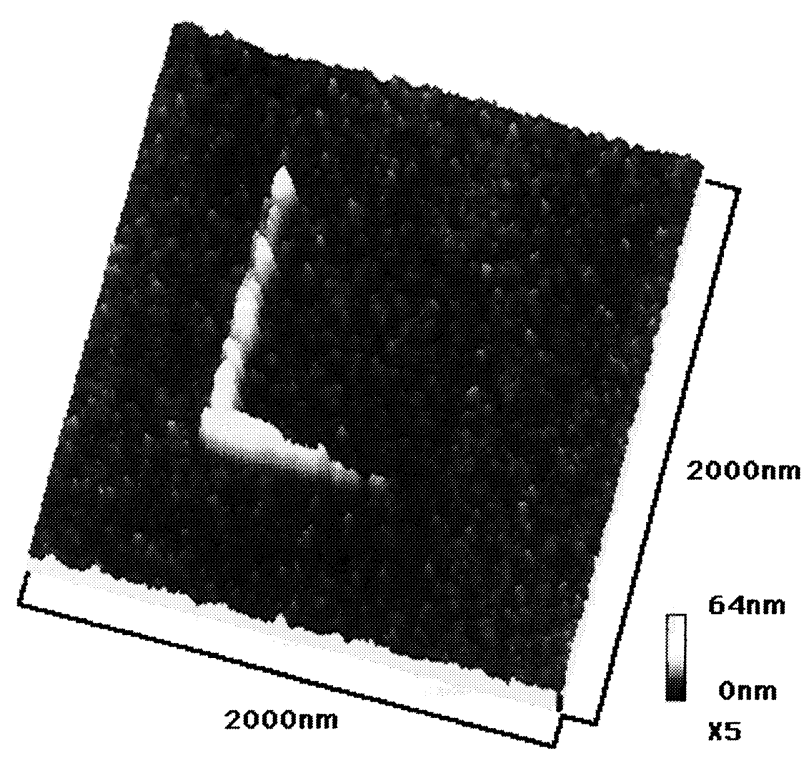

(d) movement of small particle by contact AFM.

Fig. 14 Removal of adsorbed water with contact mode scanning. 


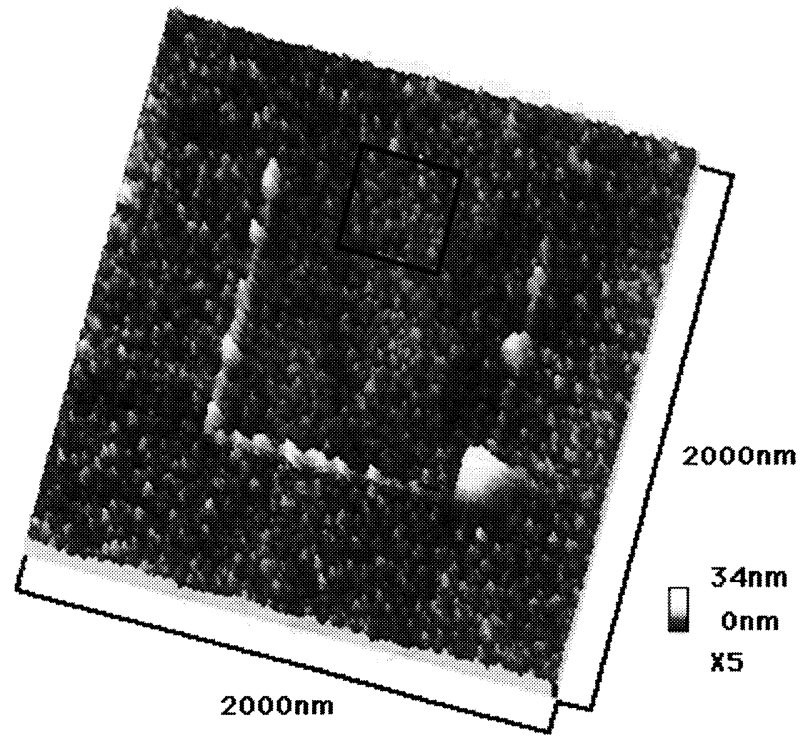

(a) $25 \% \mathrm{R} \mathrm{H}$

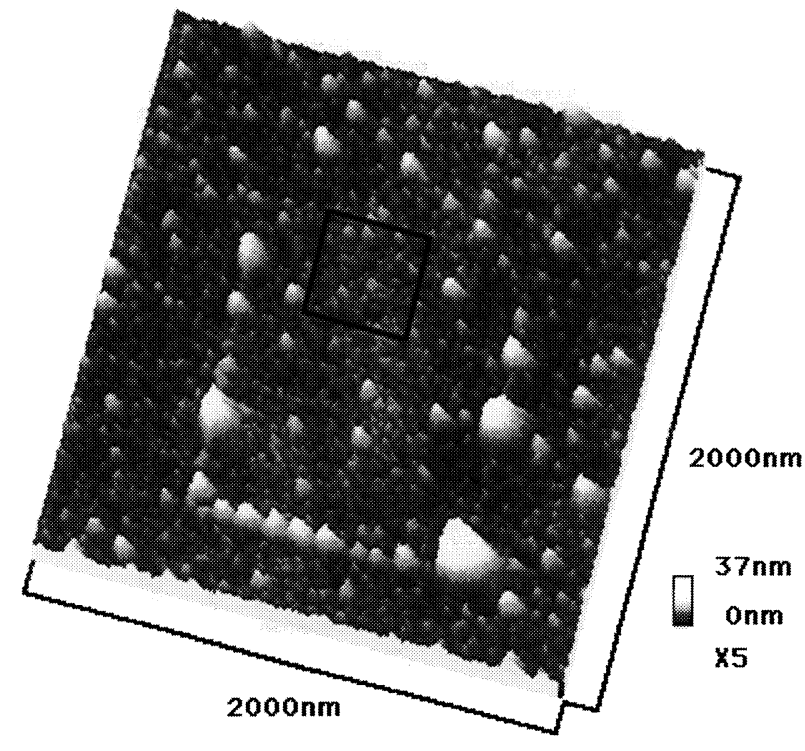

(b) $80 \% \mathrm{R} \mathrm{H}$

Fig. 15 Effect of relative humidity on the behavior of water droplets on gold.

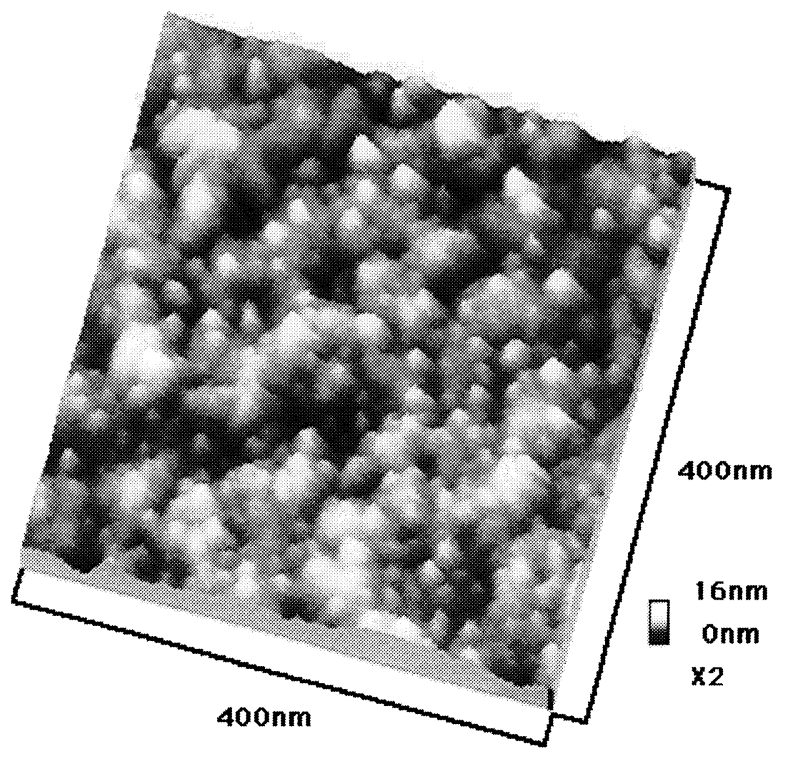

(a) $25 \% \mathrm{R} \mathrm{H}$

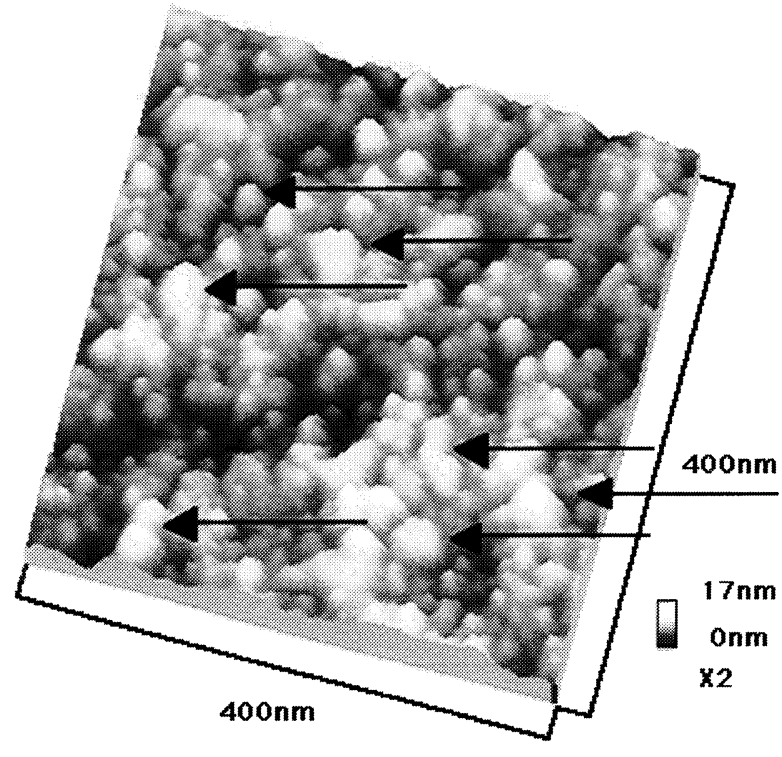

(b) $80 \% \mathrm{R} \mathrm{H}$

Fig. 16 Effect of relative humidity on the behavior of water droplets on gold. The AFM images were measured with high lateral magnification. The arrows show the nucleation of water droplets from hollowed part. 


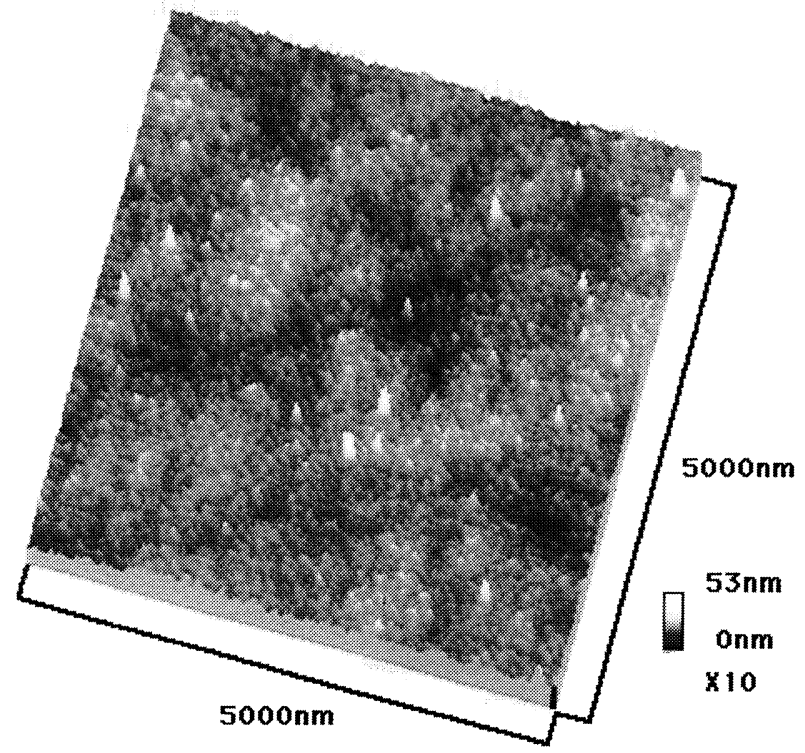

(a) $25 \% \mathrm{R} \mathrm{H}$

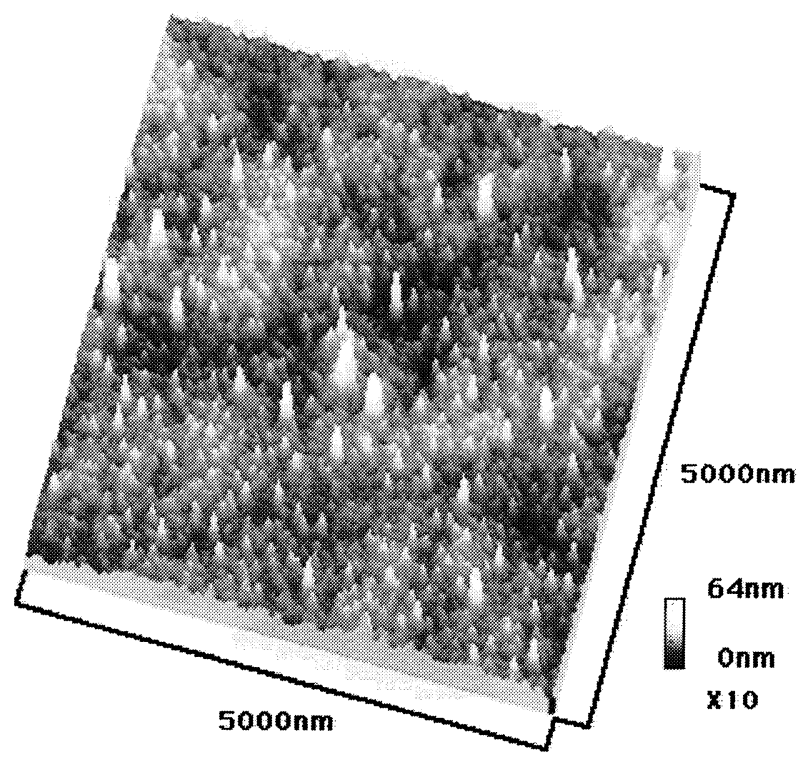

(c) $95 \% \mathrm{R} \mathrm{H}$

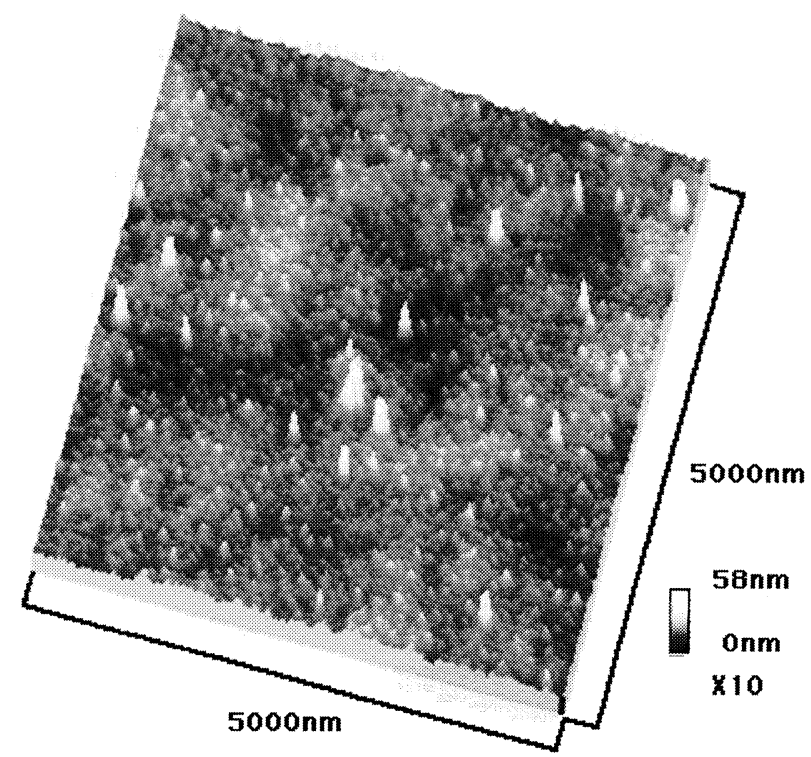

(b) $65 \% \mathrm{R} \mathrm{H}$

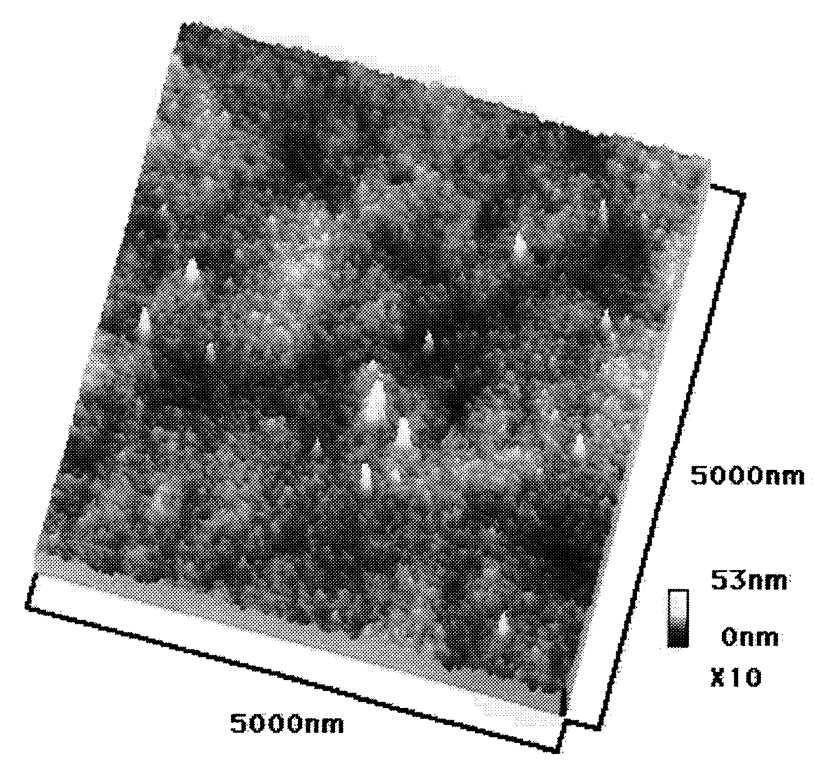

(d) $25 \% \mathrm{R} \mathrm{H}$

Fig. 17 Effect of relative humidity on the behavior of water droplets on gold. 
the ac vibration of the tip is zero, we can measure the potential of sample.

\section{Application of Surface Potential Measurement ${ }^{(21)}$}

Surface potential measurement is useful for detecting the active site in corrosion and the potential difference between liquid and solid. Figure 18 shows the in-situ observation of atmospheric corrosion on iron. The potential of corroding part is more negative than other part and the potential becomes noble when corrosion stops. Figure 19 show the shape and the potential distribution of a $\mathrm{MgCl}_{2}$ droplet on SUS304 stainless steel. Comparing with the polished surface of SUS304 stainless steel (left side of the figure), the surface of $\mathrm{MgCl}_{2}$ droplet as indicated by arrows is very smooth and flat. The potential of the SUS304 stainless steel surface with $\mathrm{MgCl}_{2}$ droplet is more negative than the surface without $\mathrm{MgCl}_{2}$ droplet and the potential becomes more negative as the thickness of the $\mathrm{MgCl}_{2}$ liquid layer increases. The shape of thin water film can not be observed when the specimen surface is rough such as the mechanically polished surface. The potential decay within an electrically double layer is big. Therefore, the potential difference is big on the thin water film of less than $10 \mathrm{~nm}$ in thickness. To confirm this, we studied the potential differences between on metal surface
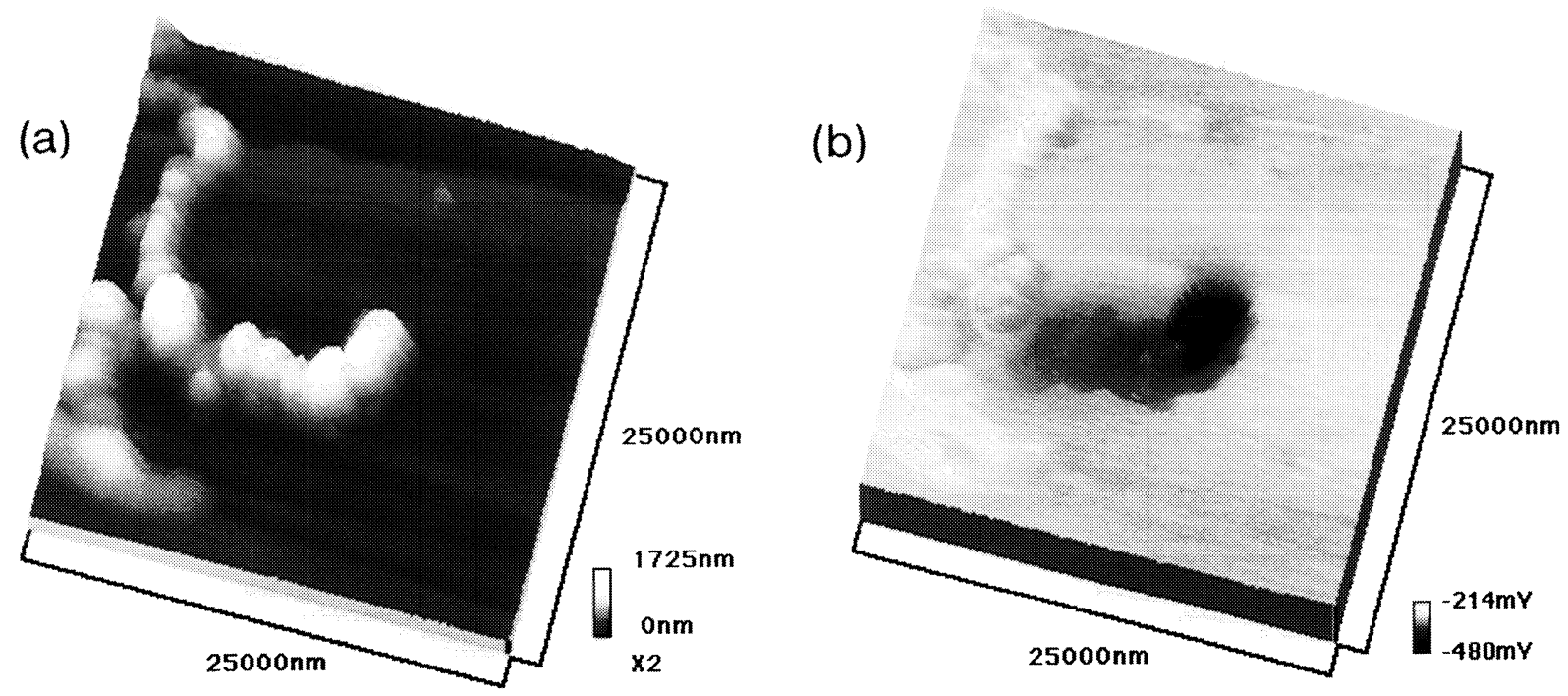

Fig. 18 KFM image of iron corroding in air. (a) Topography and (b) potential distribution.
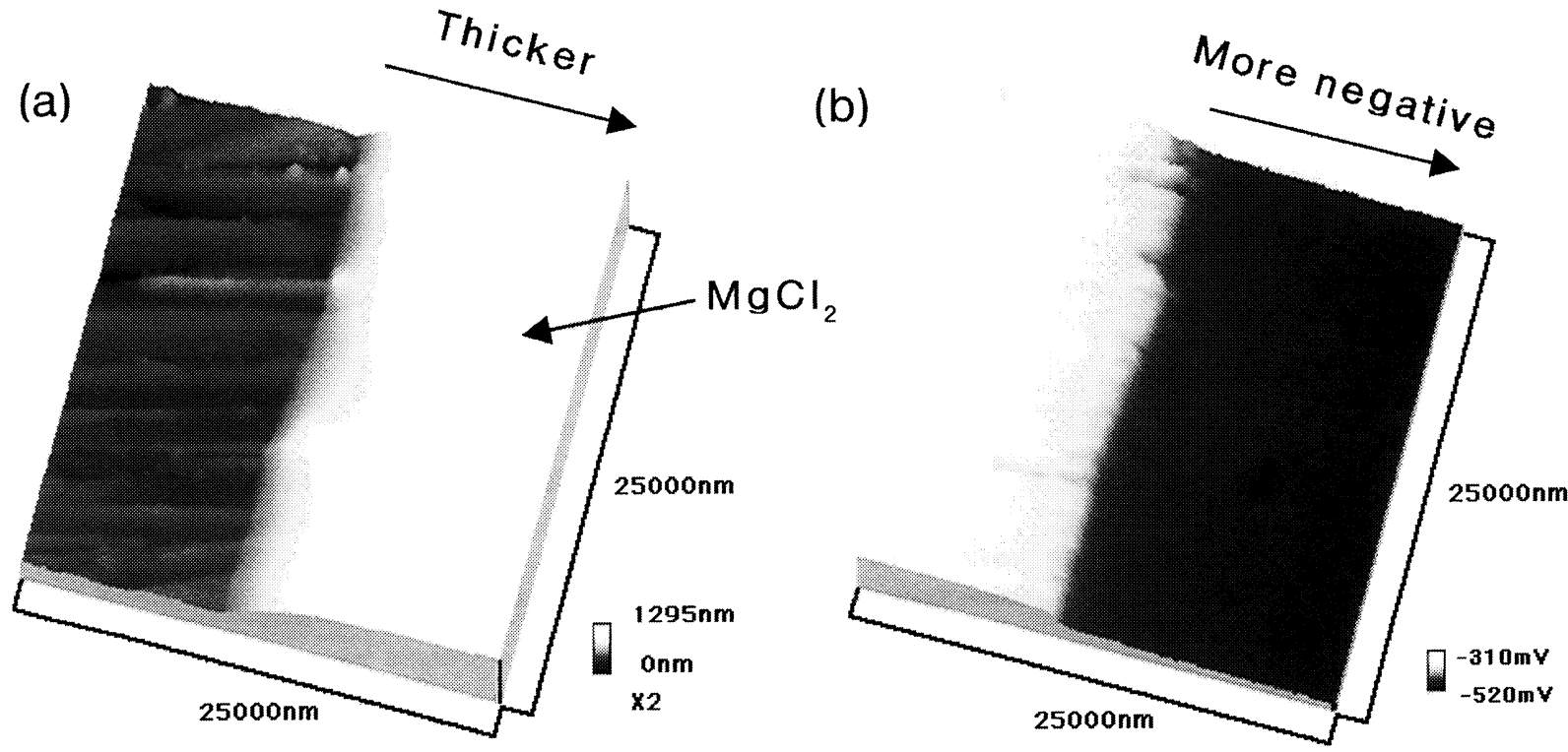

Fig. 19 KFM image of SUS304 steel with $\mathrm{MgCl}_{2}$ in air. The arrow indicates $\mathrm{MgCl}_{2}$ solution. (a) Topography and (b) potential distribution. 
poured water and dried out and on dry-polished metal surface. Figure 20 show the topography and the potential distribution of dry-polished pure iron surface. Pure water was poured right side of theses figures. The potential of the surface where water was poured was more negative than that of dry-polished part. Two reason are considered: One is the change of surface film by pouring water, and the other is the existence of thin water film. Magnifying the part where pure water was poured, special pattern of potential that can not be predicted from the topography (Fig. 21(a)) was observed as shown in Fig. 21(b). The potential of the surface of SUS304 stainless steel where a $3 \% \mathrm{NaCl}$ solution was poured (right side of the image as shown in Fig. 22) was also more negative than that of dry-polished part (Fig. 22(b)). Magnifying the part where $3 \% \mathrm{NaCl}$ solution was poured, the special potential pattern that can not be predicted from the topography (Fig. 23(a)) was also observed on the part where $3 \% \mathrm{NaCl}$ solution was poured (Fig. 23(b)). To find the factors that cause the potential pattern, contact mode scanning was done with the contact force of $1.8 \mathrm{nN}$. Figure 24 shows the shape and the potential distribution of SUS304 stainless steel after contact mode scanning in the middle region of the figure. The movement of water film occurred by the contact mode scanning and big water droplets were formed outside of scanning area
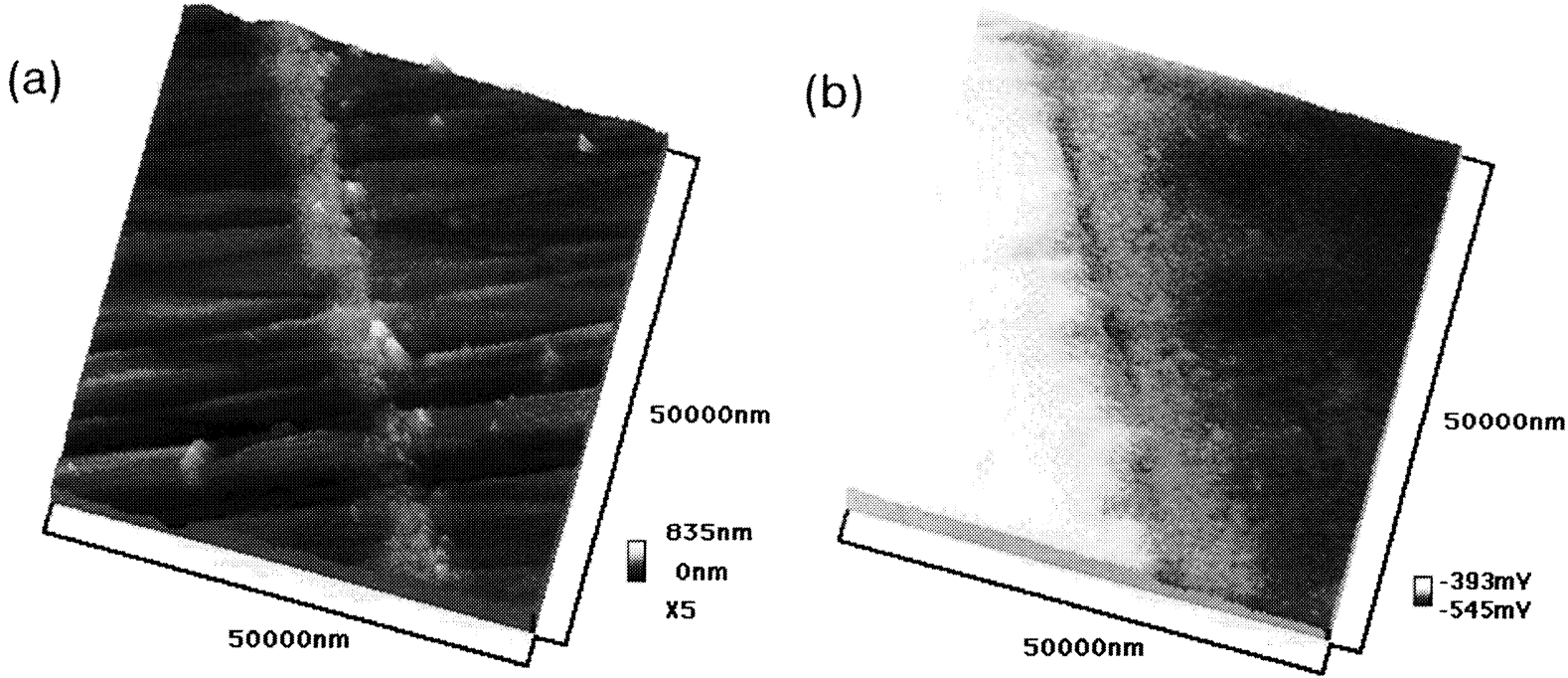

Fig. 20 (a) Topography and (b) potential distribution of pure iron surface near the boundary of dry-polished part (left) and the part pouring and dried (right).
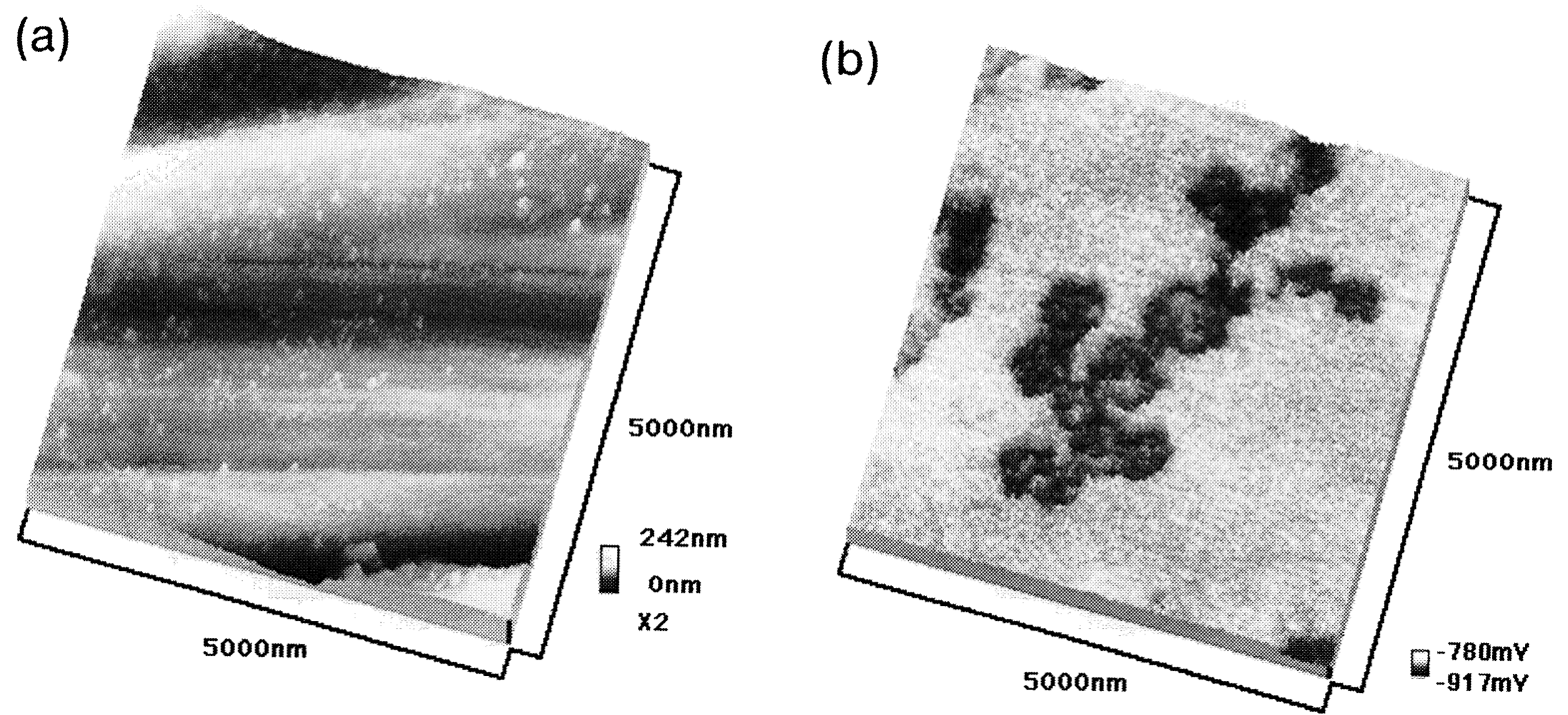

Fig. 21 Details of (a) topography and (b) potential distribution of pure iron surface pouring water and dried. 

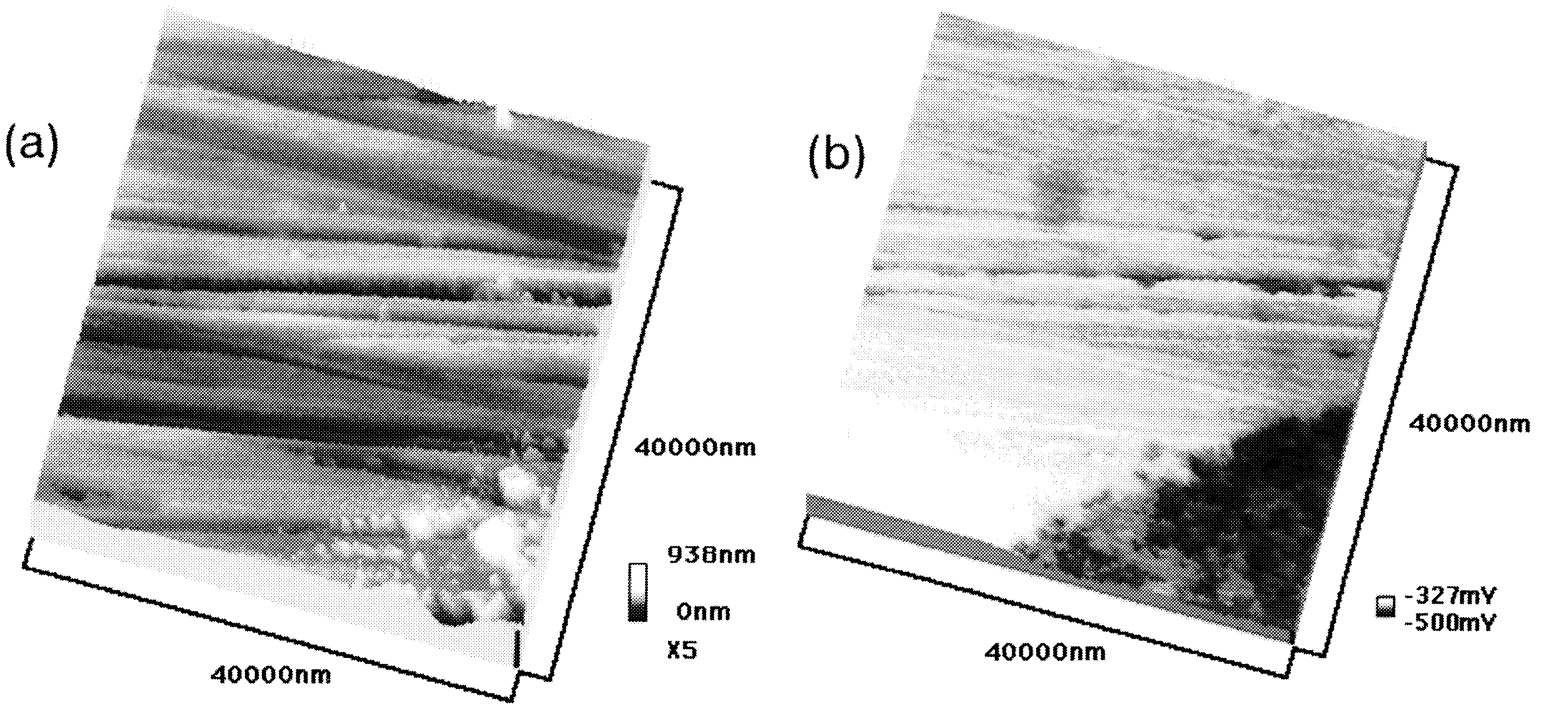

Fig. 22 (a) Topography and (b) potential distribution of SUS304 steel surface near the boundary of dry-polished part (left) and the part pouring $3 \% \mathrm{NaCl}$ solution and dried (right).
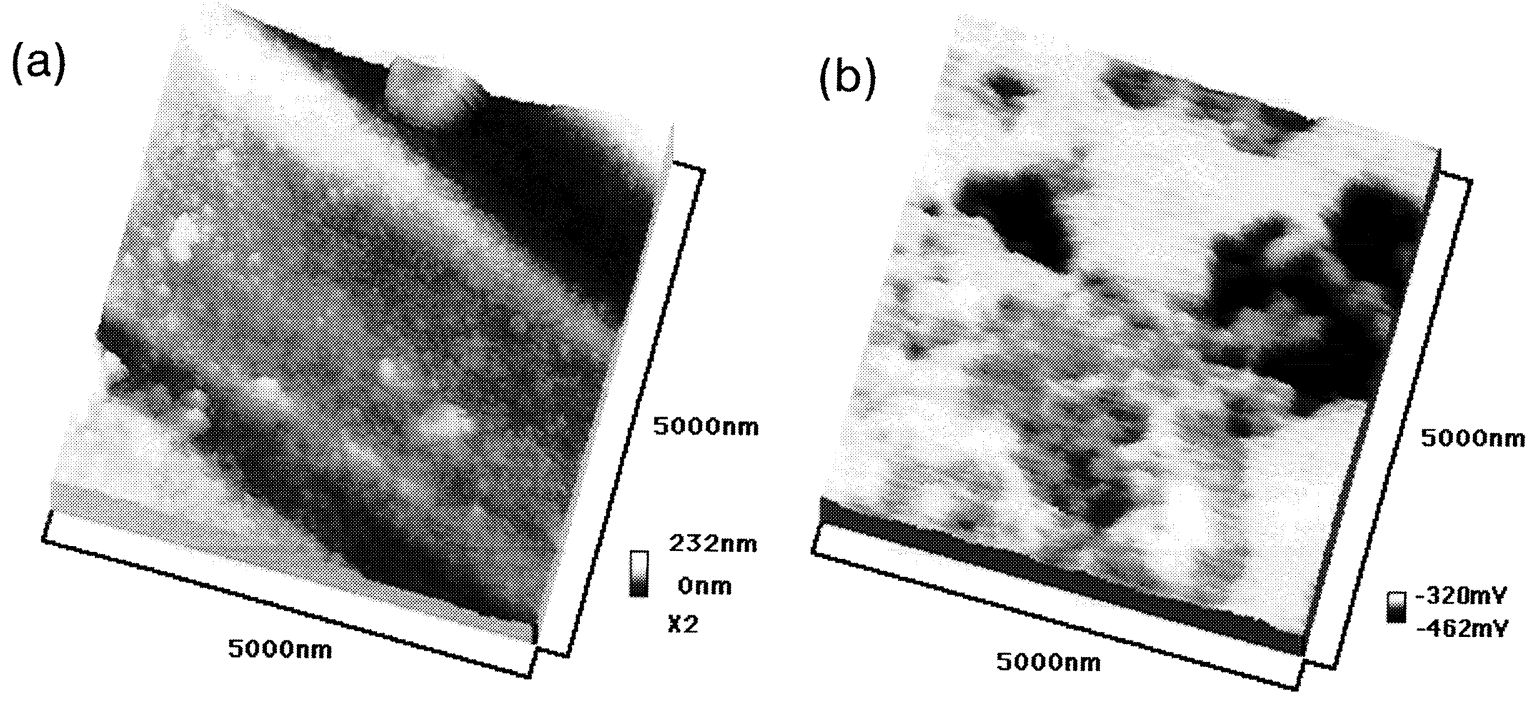

Fig. 23 Details of (a) topography and (b) potential distribution of SUS304 steel surface pouring $3 \% \mathrm{NaCl}$ solution and dried.

(a)

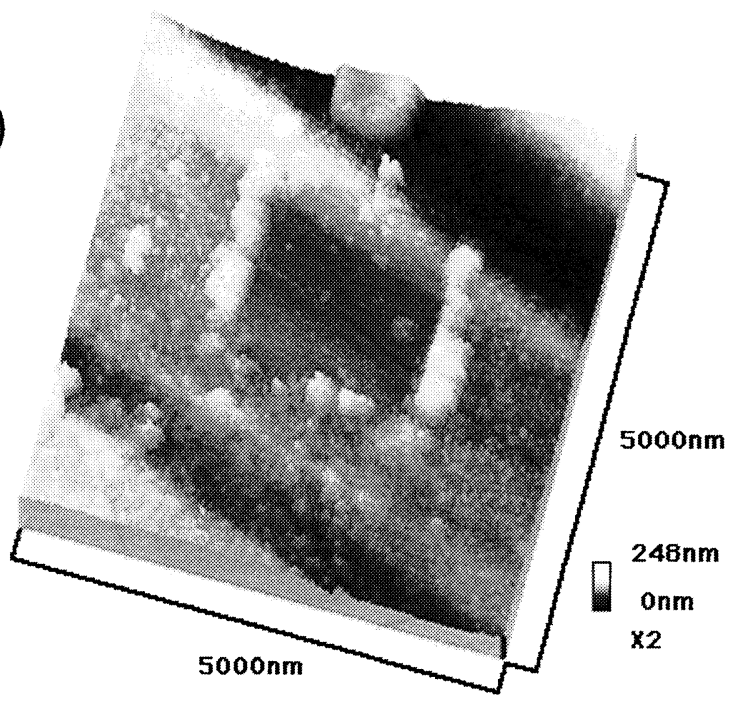

(b)

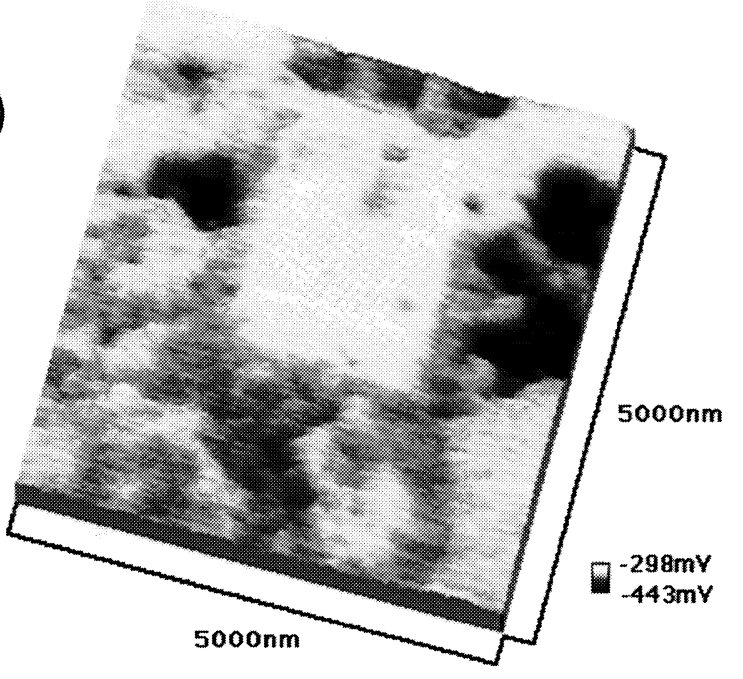

Fig. 24 Change of (a) topography and (b) potential distribution after contact mode scanning. 
(Fig. 24(a)). The potential became almost constant in the area where contact mode scanning had been done (Fig. 24(b)). From this result, it is considered that the special pattern of potential was caused by the difference of water film thickness. Thus, the distribution of thin water film can be observed by the potential measurement.

\section{Summary}

SPM is very useful device to study the nano-scopic level of surface morphology. In this paper, the application of SPM on observation of water film and water cluster is mainly discussed by using recent SPM researches of the author.

\section{REFERENCES}

(1) G. Binnig, H. Rohrer, Ch. Gerber and E. Weibel: Phys. Rev. Lett., 50 (1983), 120.

(2) T. Ohmori, K. Sakamaki and A. Fujishima: Japan Corr., Eng., 39 (1990), 564.

(3) H. Masuda: Zairyo to Kankyo, 42 (1993), 99.

(4) A. Kondo and S. Nozoe: Hyomen, 33 (1995), 782.

(5) O. Matsuoka and S. Yamamoto: Hyomen, 33 (1995), 632.
(6) M. Fujii and S. Kiyomiya: Hyomen, 32 (1994), 1.

(7) S. Morita: All about Scanning Probe Microscope, KogyouChosakai, (1992).

(8) J. Hu, X. D. Xiao and M. Salmeron: Appl. Phys. Lett., 67 (1995), 476.

(9) J. Hu, X. D. Xiao, D. F. Ogletree and M. Salmeron: Science, 268 (1995), 267.

(10) H. W. Hao, A. M. Baro and J. J. Saenz: J. Vac. Sci. Technol., B9 (1991), 1323.

(11) H. Masuda: J. Japan Inst. Metals, 61 (1997), 140.

(12) H. Masuda: J. Japan Inst. Metals, 62 (1998), 173.

(13) H. Masuda: J. Japan Inst. Metals, 62 (1998), 617.

(14) H. Masuda: J. Japan Inst. Metals, 62 (1998), 961.

(15) J. Itoh, T. Sasaki, M. Seo and T. Ishikawa: Corr. Sci., 39 (1997), 193.

(16) S. Ohshido and Y. Ishikawa: Zairyo to Kankyo, 47 (1998), 173.

(17) Y. Martin, D. W. Abraham and H. K. Wickramasinghe: Appl. Phys. Lett., 52 (1988), 1103.

(18) M. Nonnenmacher, M. P. O’Boyle and H. K. Wickramasinghe: Appl. Phys. Lett., 58 (1991),2921.

(19) J. M. R. Weaver and D. W. Abraham: J. Vac. Sci. Technol., B9 (1991), 1559

(20) M. Tanimoto and O. Vatel: J. Vac. Sci. Technol., B14 (1996), 1547.

(21) H. Masuda: J. Japan Inst. Metals, 62 (1998), 1183. 